Cite this: Phys. Chem. Chem. Phys., 2013, 15, 8662

Received 3rd December 2012, Accepted 14th March 2013 DOI: $10.1039 / c 3 c p 44343 d$

www.rsc.org/pccp

\title{
The fast Z-scan method for studying working catalytic reactors with high energy X-ray diffraction: ZSM-5 in the methanol to gasoline process $\dagger$
}

\author{
David S. Wragg, ${ }^{\star a}$ Francesca L. Bleken, ${ }^{a}$ Matthew G. O'Brien, ${ }^{b}$ Marco Di Michiel, ${ }^{c}$ \\ Helmer Fjellvåg ${ }^{a}$ and Unni Olsbye ${ }^{a}$
}

\begin{abstract}
The methanol to gasoline process over the zeolite catalyst ZSM-5 in a lab-sized reactor bed (4 mm diameter) has been studied in operando with high energy synchrotron X-ray diffraction. The fast z-scan method was used, scanning the reactor repeatedly and at speed through the X-ray beam. The X-ray diffraction data were processed using high throughput parametric Rietveld refinement to obtain real structural parameters. The diffraction data show only very subtle changes during the process and this allows us to demonstrate the combination of very large data volumes with parametric Rietveld methods to study weak features of the data. The different possible data treatment methodologies are discussed in detail and their effects on the results obtained are demonstrated. The trends in unit cell volume, zeolite channel occupancy and crystallite strain indicate that more or larger reaction intermediates are present close to the reactor outlet.
\end{abstract}

\section{Introduction}

Over the last decade X-ray diffraction studies of chemical reactions have moved from being a relatively niche area of science providing limited information on areas such as zeolite synthesis to a much more generally applicable method. ${ }^{1-21}$ Recent advances in high energy X-ray detectors ${ }^{22}$ and Rietveld processing methods ${ }^{23}$ now allow us to study reactions with excellent time resolution and even space resolution, while obtaining real crystal structure data. ${ }^{3-6,24-28}$ It is now even possible to obtain three-dimensional tomographic data for working catalysts at a speed comparable to that of some industrial catalytic reactions. ${ }^{29-32}$

One excellent method for obtaining useful data on reactions which take place in catalytic reactor beds is the Z-scanning approach - scanning the reactor at speed through the X-ray beam. This allows us to observe variations in the composition of the catalyst during the progress of the reaction, for example in the molybdenum oxide oxidation catalyst system. ${ }^{33}$ Such analysis

\footnotetext{
${ }^{a}$ inGAP Centre for Research Based Innovation and Department of Chemistry, University of Oslo, Postboks 1033, Blindern, Oslo, Norway.

E-mail: david.wragg@smn.uio.no, francesca.bleken@kjemi.uio.no,

helmer.fjellvag@kjemi.uio.no, unni.olsbye@kjemi.uio.no

${ }^{b}$ Utrecht University, Inorganic Chemistry and Catalysis, Utrecht, Utrecht,

The Netherlands.E-mail: m.g.obrien@uu.nl

${ }^{c}$ ESRF, Grenoble Cedex 9, France. E-mail: dimichie@esrf.fr

† Electronic supplementary information (ESI) available. See DOI: 10.1039/ c3cp44343d
}

is possible with relatively poor diffraction data, using single characteristic peaks to identify the phases. This very basic analysis of the X-ray data is very useful, indeed, it is probably the most common application of X-ray diffraction in general, but more sophisticated analysis can yield many levels of extra information. It is now possible not only to collect powder XRD data of suitable quality for Rietveld refinement, but also to carry out the structure refinements automatically on massive datasets with high stability using modern Rietveld software such as TOPAS academic. ${ }^{34}$ An example of this is our recent study of the development of reaction intermediates and coke in a methanol to olefin (MTO) reactor. ${ }^{25}$ The variation in the unit cell parameters of the catalyst (which vary significantly depending on the organic molecules inside the cavities), obtained from full profile Rietveld refinement, was used as an indicator to track the development and movement of reaction intermediates and coke through a tube reactor. The data obtained gave the information required to develop a new kinetic model for the process. ${ }^{25}$

In this paper we will fully describe the techniques for analysing Z-scan data with high throughput Rietveld methods, verification of the results against high quality single point synchrotron image plate data, and the possible pitfalls inherent in studying data with very small variations. The example used is the methanol to gasoline (MTG) conversion process over the highly crystalline aluminosilicate zeolite catalyst ZSM- $5 .{ }^{35}$ This catalyst has been used for conversion of methanol to fuels since 
the 1970's and has been applied at an industrial scale. ${ }^{36}$ It has a zeolite framework structure with two interlinked 10-T-atom ( $\mathrm{T}=$ tetrahedrally coordinated $\mathrm{Al}$ or $\mathrm{Si}$ ) ring channel systems; straight channels parallel to the $\left(\begin{array}{lll}0 & 1 & 0\end{array}\right)$ direction and sinusoidal or zigzag channels parallel to the $\left(\begin{array}{lll}1 & 0 & 0\end{array}\right)$ direction. The process and its zeolite catalyst have been extensively studied, particularly with respect to the mechanism of the MTG process. ${ }^{37-42}$ Computational methods, ${ }^{43,44}$ microscopy, ${ }^{45-48}$ isotopic labelling/ switching, ${ }^{49-51}$ catalyst dissolution ${ }^{52}$ and spectroscopies ${ }^{53-59}$ have all been used. Of particular interest here are the numerous powder and single crystal diffraction structural studies carried out on adsorption of hydrocarbons into ZSM-5. The groups of Mentzen and van Koningsveld in particular studied the effects of adsorbing a range of hydrocarbon and halogenated hydrocarbon molecules and methanol with detailed and careful X-ray diffraction analysis. ${ }^{60-75}$ These studies showed that very small variations in ZSM-5 unit cell volume can be observed on the adsorption of various different molecules and that the filling of the pores by different molecules can change the symmetry of the crystal structure. The high crystallinity of the zeolite catalyst and the large body of existing research on adsorption of organic molecules makes X-ray diffraction a very suitable method for studying the MTG process over ZSM-5.

It has been found that the MTG reaction is an autocatalytic reaction, the autocatalytic species being partly alkenes, partly arenes, and, to a smaller extent, other cyclic hydrocarbons. ${ }^{40}$ The relative significance of each autocatalytic species depends on a variety of parameters, such as zeotype topology, acid site density, acid strength and reaction conditions. ${ }^{40,76}$ Contact time variation experiments using the ZSM-5 catalyst at between 290 and $390{ }^{\circ} \mathrm{C}$ showed that at short contact times, methanol rapidly equilibrated with DME, and that the two molecules were subsequently converted to light alkenes, which were again converted to aromatic and paraffinic products via methylation, cyclisation and hydride transfer reactions. ${ }^{77}$

\section{Experimental}

The ZSM-5 CBV28014 catalyst $\left(\mathrm{SiO}_{2} / \mathrm{Al}_{2} \mathrm{O}_{3}\right.$ molar ratio 280) from Zeolyst International was pressed and sieved to a particle range of 0.25 to $0.42 \mathrm{~mm}$. $100 \mathrm{mg}$ of the catalyst was packed into a $4 \mathrm{~mm}$ internal diameter quartz tube with a quartz frit in the tube for the catalyst to rest upon. The resulting bed depth was $16 \mathrm{~mm}$. A special goniometer setup was constructed for the experiment on beamline ID 15b of the European Synchrotron Radiation Facility (ESRF). The tube was fitted into an L shaped Swagelok bend mounted on a Huber goniometer head. The goniometer head was in turn mounted on an xyz-stage capable of very fast Z-translations over a range of $50 \mathrm{~mm}$. Heat guns were also mounted on the xyz-stage, in order that they could be translated up and down with the reactor, maintaining the temperature on the catalyst bed during the movement of the bed. The reaction gases (helium inert gas or helium bubbled through a flask of methanol at a temperature of $20{ }^{\circ} \mathrm{C}$ ) were flowed upwards through the L-bend into the reactor at a weight hourly space velocity of $5.7 \mathrm{~g} \mathrm{MeOH}^{-1}$ catalyst $\mathrm{h}^{-1}$, X-ray diffraction data were collected on a Pixium area detector with a wavelength of $0.1426 \AA$ ( $89.965 \mathrm{KeV}$ ). The beam size was $500 \mu \mathrm{m}$. The set-up allowed us to move the catalyst bed up through the X-ray beam at a rate of $0.5 \mathrm{~mm} \mathrm{~s}^{-1}$ with PXRD patterns being collected at 1 second intervals. The product stream was analysed using a European Spectrometry Systems ecoSys-P Man-Portable mass spectrometer with capillary inlet and heated inlet tubes. The data were scaled and reduced to $2 \mathrm{D}$ powder patterns using the program DATASQUEEZE. The instrumental peak function was characterised by a $\tan -2 \theta$ broadening parameter as described by O'Brien et al. ${ }^{26}$ using NIST SRM660 Lanthanum hexaboride. This dataset was also used to calculate the sample to detector distance $(1472.5 \mathrm{~mm})$ and flat plate detector geometrical corrections used in data reduction.

Data for validation of the behaviour of the catalyst were collected on beamline BM01A of the ESRF (The Swiss Norwegian beamline) using the capillary reactor described by Norby et al. and used in numerous PXRD studies of catalysts and other systems. ${ }^{3-5,18-21,78-80}$ Helium bubbled through methanol at $20{ }^{\circ} \mathrm{C}$ was fed over the catalyst at a rate of $20 \mathrm{ml} \mathrm{min}{ }^{-1}$. Diffraction data were collected at a wavelength of $0.6978 \AA$ on a MAR345 image plate detector and integrated into 2D powder patterns using FIT2D. ${ }^{81,82}$

The reaction was carried out at a temperature of $350{ }^{\circ} \mathrm{C}$ in both the quartz tube and capillary reactors, with the catalyst being activated prior to reaction by heating to $350{ }^{\circ} \mathrm{C}$ under a flow of helium gas. The temperature in the capillary setup was calibrated using the thermal expansion of silver while the tube reactor temperature was calibrated using a thermocouple.

The data were analysed using TOPAS academic with a parametric Rietveld approach. Polarization of the X-ray beam was corrected for in the Rietveld refinement. The specific methods used for analysing the data and the variations between different analytical methodologies are discussed in more detail below. Data were input into text files for processing with Microsoft Excel and OriginLab Origin 8.6. A typical TOPAS input file for the parametric refinement is included as ESI. $\nmid$ Curve fitting was carried out in Origin 8.6.

\section{Results and discussion}

\section{A. Analysis of the data}

The data on the MTG were analysed by a parametric method using the structural model of as synthesised ZSM-5 reported by Van Koningsveld et $a l^{83}$ The stability of the TOPAS Rietveld algorithm allows us to use the occupancy factors of the atoms in the template as dummy atoms to quantify the electron density built up in the pores, a method used previously for in situ studies of the MTO process. ${ }^{3}$ The occupancy of these sites refines to zero when there is no electron density present in the pores, and was linked to a single refined parameter for each powder pattern. Each pattern has an independent 7-term Chebyshev polynomial background function with a broad Lorentzian peak used in addition to model the amorphous bump in the background caused by the quartz reactor tube (fixed position, intensity refined independently for each pattern, broadening linked across all 
patterns in the dataset, see below). The lattice parameters of the structure were refined for each pattern as restricted by symmetry (orthorhombic space group number 62, Pnma) and the broadening of the peaks in each pattern was modelled with the TOPAS Lorentzian strain broadening macro, on the assumption that strain in the crystallites rather than particle size would be influenced by any changes caused by the build-up of reaction intermediates inside the zeolite catalyst during reaction as for SAPO-34 in the MTO process ${ }^{4,6}$ (sample related broadening of powder diffraction peaks being caused principally by crystallite size and strain). The scale, adsorption correction and zero error were linked between the datasets and treated in different ways in order to test the effect of the different methods. The ability to link parameters between multiple datasets which are refined simultaneously in a simple and intuitive way (they are simply given the same parameter name whenever they occur in the input file) is a major advantage of the TOPAS Rietveld refinement program. This is a key part of the strategy for Rietveld analysis of fast Z-scan high energy powder X-ray diffraction (HEPXRD) data - limiting the number of parameters in the large datasets and also increasing the precision in their determination. In the analysis of the MTG data we experimented with linking of various parameters between the datasets. The main linked parameters were zero point, scale factor, position and broadening of the quartz background peak and adsorption correction. For the main analysis of the complete dataset a 2-theta range of 0.5 to $6.95^{\circ}$ was used (min $d$-spacing $=1.176 \AA$ ).

When dealing with very large datasets it is necessary to separate the data into batches due to memory limitations (the least squares matrix must be held in the RAM of the processing computer). This means that it is important to know how certain parameters which should be the same in all cases vary between the batches. We, therefore investigated the influence of the zero point on the datasets - studying the difference between refining batches with a fixed zero point or allowing the zero point to refine separately between the batches and hoping that it reaches the same value in all cases. Allowing different values of the zero point correction led to a significant oscillation in this parameter between two values $(-0.00062$ and -0.00053$)$ which influenced the lattice parameters to a very significant degree (a cell volume average of $5355 \AA^{3}$ for zero error = -0.00062 compared to $5368 \AA^{3}$ for zero error $=-0.00053$ ). Because of these variations due to correlation of the lattice parameters and the zero point we decided to fix the zero point for all refinements. We note however that this effect does not change the actual trends in the data: the same percentage variations are observed in the unit cell volume regardless of the zero point chosen. This suggests that despite the correlation with the zero point the lattice parameters are converging to values representative of the physical behaviour (Fig. 1). The data used in the contour plots presented below were obtained with a fixed zero point error correction of -0.00062 .

The method used to refine the position of the quartz background peak was also varied: free refinement for all powder patterns, fixed position and linked refinement in each batch were tested. The results showed very little variation in the unit

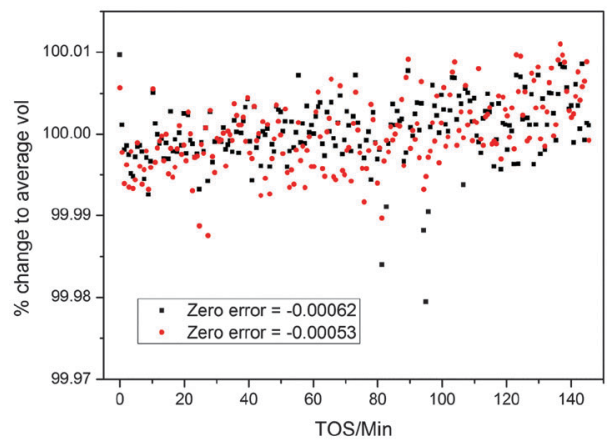

Fig. 1 Percentage change in the volume of ZSM-5 for two different final refined values of the zero error correction in the parametric Rietveld refinement, during the MTG process in a slice of the reactor $3.5 \mathrm{~mm}$ from the inlet. TOS stands for "time on stream": the time for which the catalyst bed has been exposed to the methanol reagent gas. Refinement was carried out along the reactor slice (see Section B). Note the upward trend in the volume/average volume percentage.

cell volume and channel occupancy for the different methods; however, the spread of values is noticeably greater for the free refinement data (Fig. 2a) and slightly greater for the fixed position method (note points at TOS $=24.6$, 77.9 and 99 minutes in the channel occupancy plot, Fig. 2b). In view of this we used the parametric method to refine the quartz background peak position in the main refinements.

\section{B. Influence of the batch shape}

The batches used in the analysis of $z$-scan data have a clear influence on the results (see Fig. 1 and $2 \mathrm{a}$ in ref. 10). We therefore carried out our analysis in two ways. In the "block analysis" the batches were formed of 10 complete scans of the reactor (each scan comprises data from all 32 slices of the reactor). The "linear" analysis used batches created from a single slice of the reactor. The overall trends seen in both types of refinement should be the same. When the data are plotted as contour maps in time and space the results of the two methods are clearly closely related for channel occupancy (Fig. 3a and b) where clear variations can be observed.

Several features of the channel occupancy plots are reproduced between the block and linear analyses, the most important being the onset of a significant increase in occupancy across the reactor bed at 25 minutes on stream; an area of increased occupancy at the outlet end of the reactor (beginning at around $14 \mathrm{~mm}$ from the inlet) and two streaks of slightly increased occupancy running vertically up the reactor bed at TOS $=82$ and 95 minutes. The significance of these features will be further discussed in Section $\mathrm{D}$ below. The block method shows more periodic variations in the reactor height dimension.

In the case of unit cell variation the changes observed are so small that clear differences can be observed between the two batching methods (Fig. 4a and b). In order to compare the small variations in all parts of the reactor on the same scale the cell volumes are presented as percentage variations around the average value of the cell volume for each slice of the reactor bed.

The plot in Fig. 4a shows clear evidence of periodic variation along the reactor height dimension as for channel occupancy. 

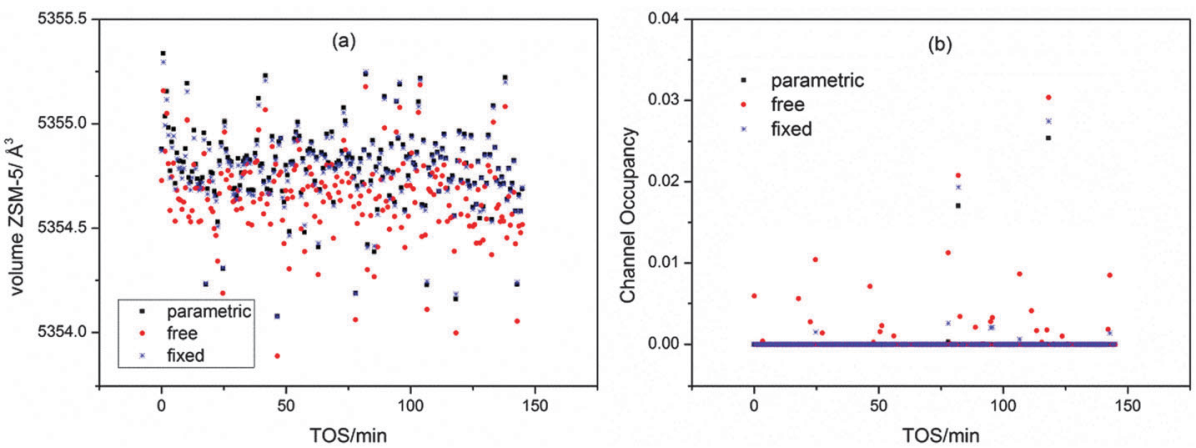

Fig. 2 Influence of the refinement method used for the quartz peak on the cell volume (a) and the channel occupancy (b) for the 0 mm slice of the MTG reactor.
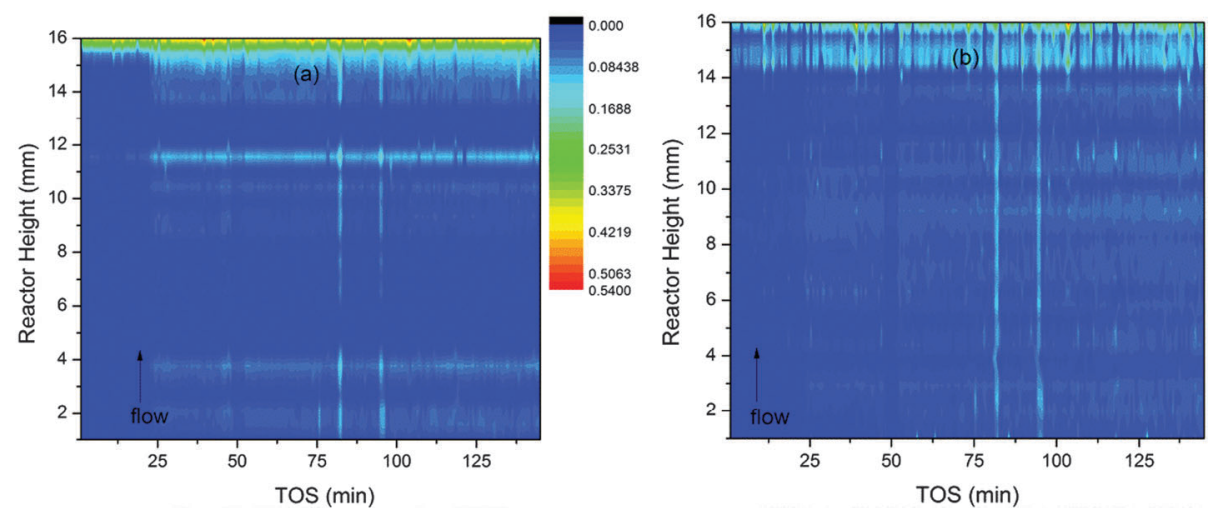

Fig. 3 Contour plots of the variation of channel occupancy (colour scale) in ZSM-5 during the MTG conversion process. The occupancy is represented by the colour scale. Plot (a) is based on data obtained by block refinement and plot (b) on linear refinement data.
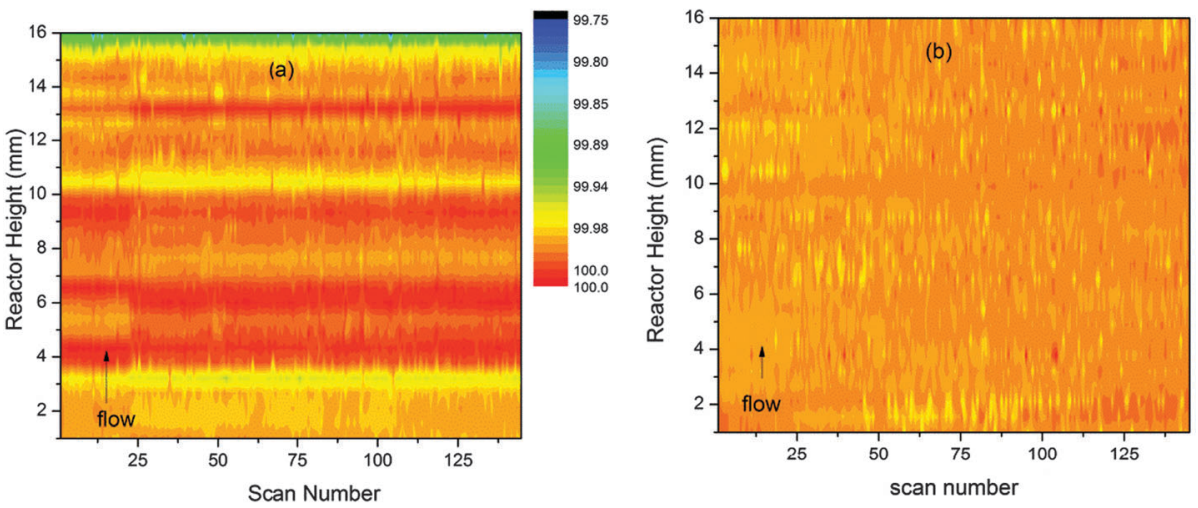

Fig. 4 Percentage variations (colour scale) in the unit cell volume of ZSM-5 during the MTG conversion process shown as contour plots in time and space. Plot (a) shows values obtained by the block refinement method and (b) values obtained by linear analysis.

This may well be a sign of instability in the block refinement strategy. The values obtained by the linear method are much smoother (Fig. 4b), to the point of showing almost no variation. However, careful examination indicates that a slight growth in the unit cell occurs across the reactor bed with time, with the biggest expansion observed at the outlet end of the bed. These results suggest that the linear refinement method is superior for analysis of z-scan data.
Using standard 2-dimensional plots of the unit cell variation for individual slices of the bed shows the changes more clearly. The lines of best fit obtained by linear regression of the data for each slice of the bed show slightly different slopes and further analysis of these for all slices of the reactor bed suggests a weak trend of increasing slope higher up the bed (Fig. 5).

Clearly it is difficult to obtain useful data on this system from the unit cell volume variations, as they are so small. 

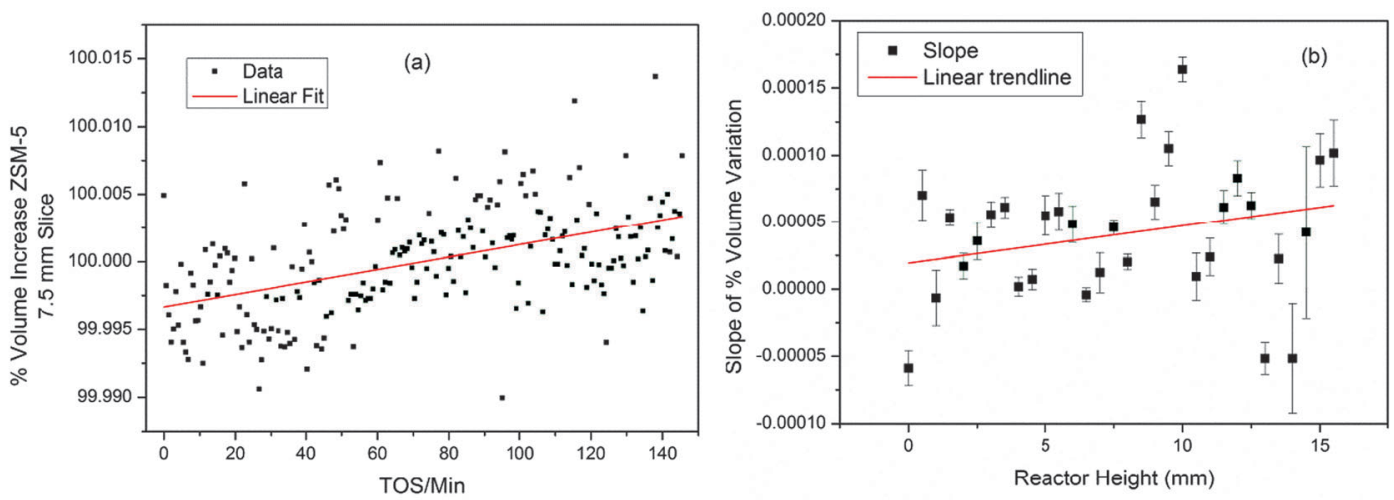

Fig. 5 (a) Volume change in ZSM-5 (expressed as a percentage of the average volume) for the $7.5 \mathrm{~mm}$ slice of the MTG reactor; (b) plot of slopes of the linear regression lines in the volume data for all slices of the reactor. Linear regression lines are shown to illustrate the trends in the data.

Furthermore, it was not possible to obtain good difference Fourier maps from the z-scan data, even when the range of $d$-spacing was extended to $0.88 \AA$, however, using the dummy atom method the occupancy can be quantified, and this proves much more revealing than the unit cell volume. The trend in the channel occupancy varies with height in the bed, as can be seen from the contour plot in Fig. 2. The variations are well illustrated by 2-D plots of the reactor slices (Fig. 6). At the inlet end of the reactor a linear growth in occupancy is observed (a); the mid-section plots show a similar maximum level of occupancy but the maximum point is reached faster, with a rapid increase in occupancy until TOS $=20$ minutes followed by a reduction in the slope (b); at the outlet end of the reactor a similar curve shape is observed in the middle section, but with a higher final occupancy level (c).

These plots are easy to compare with the data from a single point measurement in a capillary reactor (Fig. 7). The capillary geometry gives better quality data than the large tube reactor as the sample to detector distance and detector geometry are more precisely defined. The plots clearly display the same trends seen in the z-scan experiment, validating the observations from the slightly lower quality data obtained for the bigger reactor. The trend in the channel occupancy from the single point measurements is closer to that observed in the middle of the reactor bed, though some delay in the initiation of the growth in occupancy is observed in the single point measurement.
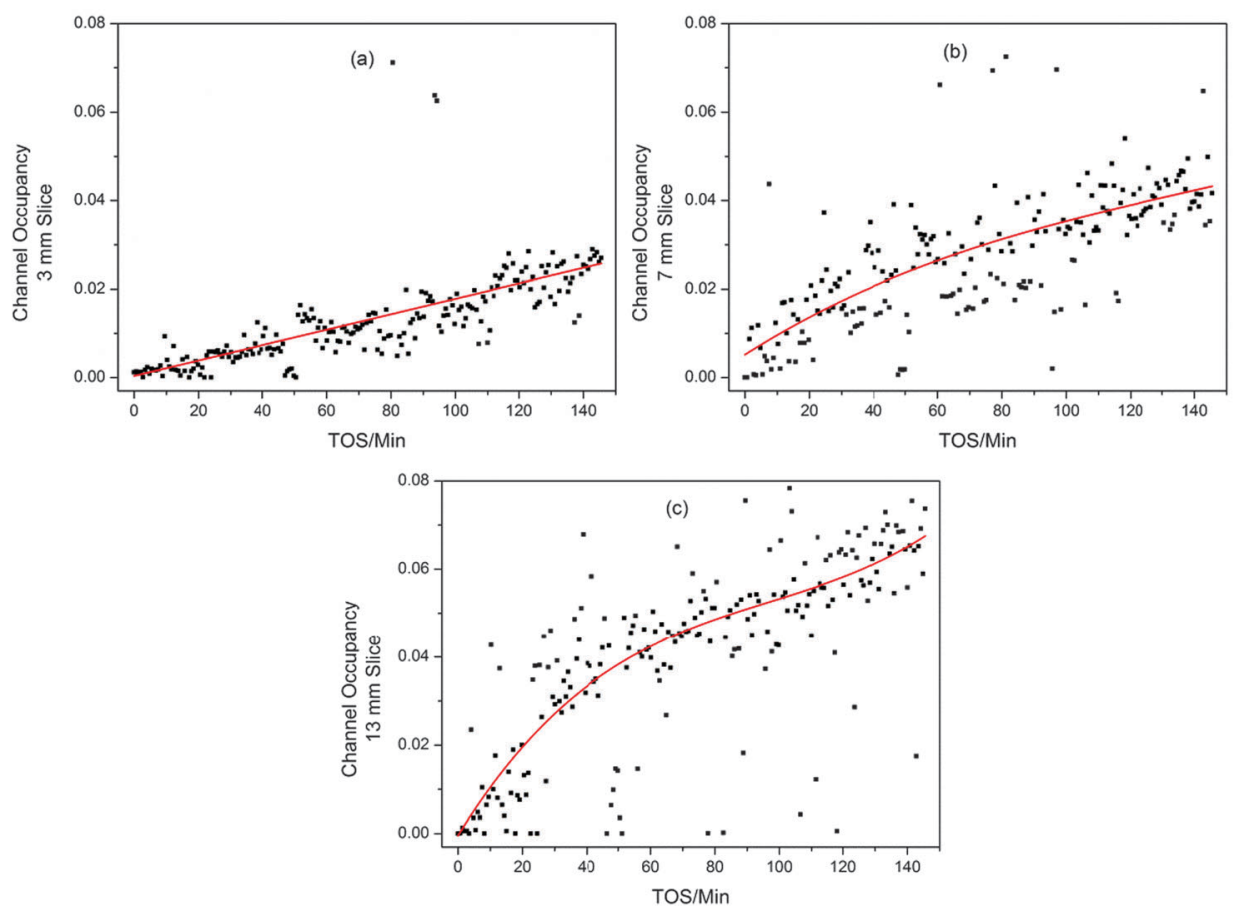

Fig. 6 2D Plots illustrating the different trends in ZSM-5 channel occupancy development during the MTG process for different slices of the reactor bed; (a) 3 mm up the reactor, (b) $7 \mathrm{~mm}$ and (c) $13 \mathrm{~mm}$. Linear (a) and 3rd order polynomial (b and c) fits are used to pick out the trends in the data. Note that the fit statistics for linear and polynomial fitting of (b) are similar. 

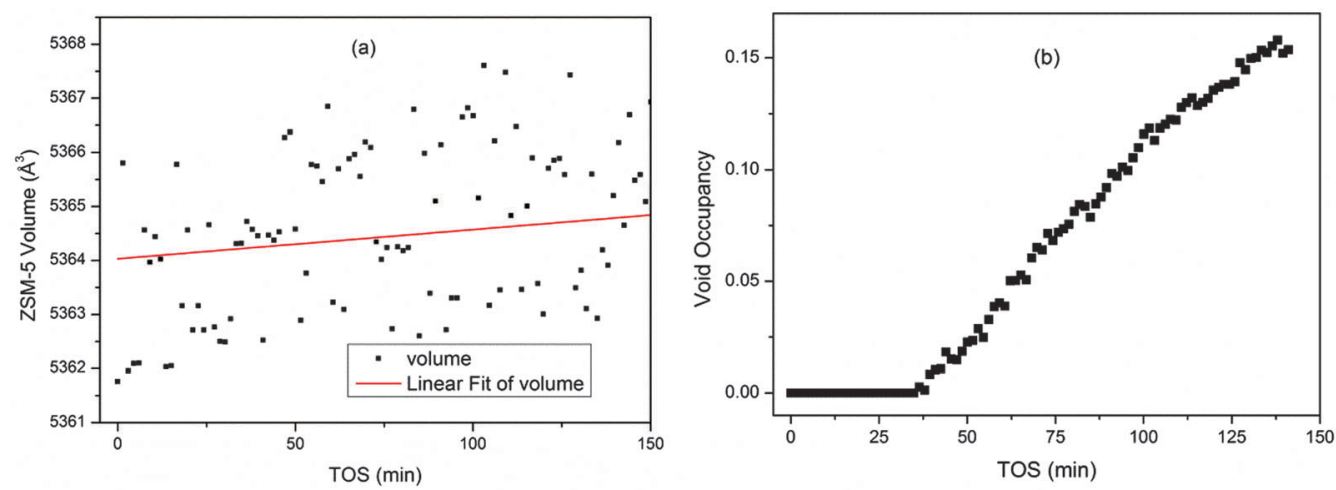

Fig. 7 Plots of the unit cell volume (a) and channel occupancy (b) of ZSM-5 during the MTG process from single point measurements in a capillary reactor.

The maximum occupancy value from the capillary reactor is higher than that observed from the z-scan data, however, it is unwise to compare absolute values of channel occupancy produced by different experimental set ups, and we must content ourselves to note the similarity of the curve shapes.

\section{Calculation of errors}

The normal method for determination of errors from Rietveld refinement is through use of a covariance matrix. For the very large datasets involved in experiments of the type described here this is an exceptionally slow process. Fortunately TOPAS supports the "bootstrap" method of error determination which is based on repeated resampling of limited areas of the data range. ${ }^{84}$ Since the convergence of the Rietveld refinements required is very fast (even for multiple datasets) this method is highly recommended. The current version of TOPAS academic does not, unfortunately, support the output of bootstrap errors to text files (a huge advantage when dealing with large datasets), but we believe this has been remedied in the new version (TOPAS 5) to be released in $2013 .^{85}$

\section{Catalytic activity and selectivity}

Mass spectrometry (MS) responses characteristic for methanol $(\mathrm{m} / \mathrm{z} 31)$, DME $(\mathrm{m} / \mathrm{z} 46)$ and propene $(\mathrm{m} / \mathrm{z} 42)$ versus time on stream are shown in Fig. 8. Response characteristics for butane $(\mathrm{m} / \mathrm{z} 58)$, butene $(\mathrm{m} / \mathrm{z} 56)$ and propane $(\mathrm{m} / \mathrm{z} 44)$ were also measured, but their time dependence did not deviate from that of propene, and they were therefore omitted from the figure for clarity.

Two features are apparent from the data in Fig. 8: first, methanol and DME responses were both non-zero throughout the experiment, showing that the conversion level was less than $100 \%$. Furthermore, the relative fractions of methanol, DME and propene (or any of the other measured products, see above) in the reactor effluent were stable during the experiment, showing that neither the conversion nor the product selectivity changed with time on stream. This behaviour is distinctively different from that previously observed when feeding methanol over a SAPO-34 catalyst under similar conditions: In that experiment, the methanol conversion was seen to increase, then

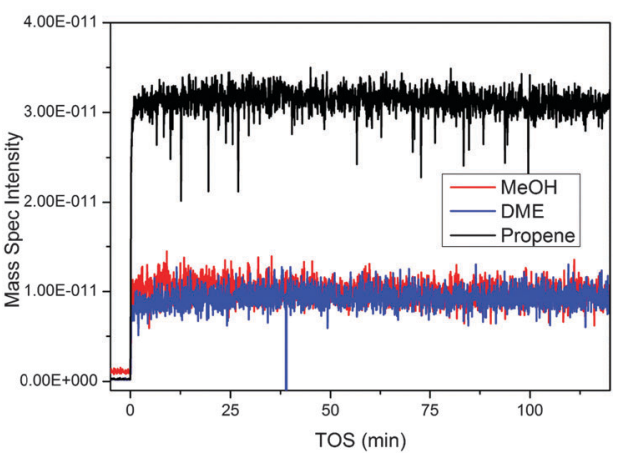

Fig. 8 Mass spectrometry data from the MTG process over ZSM-5 collected from the outlet of the z-scanning reactor system. Propene is used as an indicator of the hydrocarbon output; similar traces are observed for other product hydrocarbons.

reach a maximum value and subsequently decrease, during the z-scan experiment. ${ }^{4,25}$

The observed difference between the two zeotypes as MTO catalysts is in line with conventional tests of the two materials, with ZSM-5 gaining rapidly a steady-state activity and maintaining this stable activity level for several days, while SAPO-34 generally goes to the zero conversion level after a few hours on stream. ${ }^{40,86}$

\section{E. Interpretation of the MTG data}

X-ray diffraction structural studies of adsorbed molecules in ZSM-5 have revealed a flexible structure with rather complicated behaviour with some adsorbed molecules able to change the symmetry of the crystal structure. ${ }^{60-75}$ The symmetry changes seem to be related to filling of the sinusoidal channels of the zeolite framework. Filling of the channels also leads to expansion of the unit cell compared to the activated, empty structure. Larger molecules which occupy the intersections of the channels cause small or negative expansion (Table 1).

The small expansions (around $0.01 \%$ ) we observe during the MTG process suggest that even during an experiment under flowing conditions there occurs some build-up of materials inside the channels of the zeolite catalyst. Despite the fact that it was not possible to obtain useful difference Fourier maps 


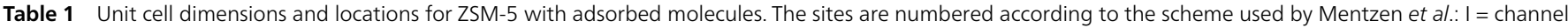
intersections, II = sinusoidal channels, III = straight channels. Volume changes are based on the calcined ZSM-5 structure reported by van Koningsveld ${ }^{87}$

\begin{tabular}{|c|c|c|c|c|c|c|c|c|}
\hline Adsorbate & $a$ & $b$ & $c$ & $\beta$ & Volume & $\%$ Volume change & Position & Symmetry change? \\
\hline None $^{87}$ & 20.078 & 19.894 & 13.372 & 90 & 5341.20 & 0 & None & No \\
\hline 4-Nitroaniline $\mathrm{e}^{70}$ & 19.96 & 19.941 & 13.367 & 90 & 5320.37 & -0.39 & I & No \\
\hline Benzene $\mathrm{e}^{71}$ & 19.996 & 19.935 & 13.427 & 90 & 5352.27 & 0.207 & I, II & Yes \\
\hline Hexane $^{74}$ & 19.8247 & 20.1292 & 13.451 & 90.3 & 5367.63 & 0.495 & II, III & Yes \\
\hline Methanol $^{65}$ & 20.118 & 19.884 & 13.382 & 90.5 & 5352.94 & 0.220 & I, II, III & Yes \\
\hline Naphthalene $^{67}$ & 19.919 & 19.955 & 13.357 & 90 & 5309.19 & -0.599 & I & No \\
\hline Naphthalene ${ }^{63}$ & 19.948 & 19.98 & 13.37 & 90 & 5328.76 & -0.233 & I & No \\
\hline$p$-Chlorotoluene ${ }^{62}$ & 20.017 & 19.935 & 13.377 & 90 & 5337.94 & -0.061 & I & No \\
\hline$p$-Dibromobenzene ${ }^{62}$ & 20.032 & 19.93 & 13.379 & 90 & 5341.40 & 0.004 & I & No \\
\hline$p$-Dichlorobenzene ${ }^{62}$ & 20.018 & 19.92 & 13.37 & 90 & 5331.40 & -0.183 & I & No \\
\hline$p$-Dichlorobenzene ${ }^{64}$ & 20.116 & 19.828 & 13.436 & 90 & 5359.08 & 0.335 & I, II & Yes \\
\hline$p$-Dichlorobenzene, high loading ${ }^{69}$ & 20.102 & 19.797 & 13.436 & 90 & 5346.98 & 0.108 & I, II & Yes \\
\hline$p$-Dichlorobenzene, low loading ${ }^{68}$ & 20.009 & 19.909 & 13.366 & 90 & 5324.47 & -0.313 & I & No \\
\hline$p$-Xylene ${ }^{62}$ & 20.025 & 19.91 & 13.374 & 90 & 5332.18 & -0.169 & I & No \\
\hline$p$-Xylene $e^{60}$ & 20.121 & 19.82 & 13.438 & 90 & 5359.05 & 0.334 & I, II & Yes \\
\hline Toluene ${ }^{75}$ & 20.099 & 19.844 & 13.424 & 90 & 5354.09 & 0.241 & I, II & Yes \\
\hline Xylene $^{66}$ & 20.021 & 19.9331 & 13.3809 & 90 & 5340.05 & -0.022 & I & No \\
\hline
\end{tabular}

from the data we suggest in view of the results summarised in Table 1 that the intermediates are not limited to the channel intersections. The increased rate of volume increase at the outlet end of the reactor suggests that either (1) organic molecules build up to high concentrations faster there or (2) larger organics which are not confined to the intersections are present there. Clearly the feed at the outlet end of the reactor bed has a longer contact time with the catalyst and so we expect that larger molecules would be most likely to be found there as they require more reaction steps to develop from methanol.

Due to the autocatalytic nature of the MTG reaction (see Introduction) the build-up of organic molecules is expected to proceed faster after a critical amount of autocatalytic species have been formed, the so-called critical contact time. ${ }^{76}$ The data reported in Fig. 6, which show an increasing slope of the channel occupancy versus time on stream curves with increasing contact time, is in line with such a model. A similar distribution of autocatalytic species and coke was observed by Schulz as colour changes in microscopic examination of a large reactor bed ${ }^{88}$ and we observed a similar pattern of intermediate and coke distribution driven by the flow rate of a fixed bed MTO reactor. ${ }^{25}$ Bleken et al. have also shown that in some cases the section of an MTG reactor bed closest to the inlet can be entirely inert. ${ }^{76}$ The observation of a constant methanol conversion level with time on stream (Fig. 8), in spite of an increasing amount of product molecules (which also act as autocatalytic species) in the catalyst channels, is more surprising. This observation may suggest that the quantity of such species is already sufficient for a zero order reaction rate at the start of the experiment. Or, the added channel occupancy with time on stream may proceed in parts of the catalyst crystals which are less important for effluent product formation. Previous ex situ analysis of retained aromatic molecules in a ZSM-5 catalyst after MTG testing at $350{ }^{\circ} \mathrm{C}$ showed no correlation between the amount of such species and the methanol conversion level, ${ }^{89}$ in line with the results of the present study. More studies, preferably under conditions with shorter contact time or lower temperatures, thus leading to a lower initial conversion and, possibly, more rapid deactivation, would be required to confirm or disprove either of the two hypotheses above.

\section{F. Is the ZSM-5 catalyst under strain during the MTG process?}

It has previously been shown that the build-up of reaction intermediates during the MTO process causes an increase in strain in the aluminophosphate framework catalysts SAPO-34 and SAPO-18. ${ }^{3,4,6}$ Flexibility of the framework is actually necessary to incorporate some of the intermediate/coke molecules found in these structures after the MTO process, ${ }^{6}$ however it is suspected that the strain associated with the flexing of the structure may contribute towards long term deactivation of the catalyst. ${ }^{90}$ The contour plot of the strain data from the MTG z-scan experiment shows little evidence of change and this is consistent with the very small changes in unit cell volume observed in the time-scale of the synchrotron experiment (Fig. 9a).

Looking at the linear slices through the reactor at 3, 6.5 and $13 \mathrm{~mm}$, we see signs of increasing strain as the reaction progresses (Fig. 9b-d). It is also possible to plot the channel occupancy vs. strain for these slices (Fig. 9b-d, insets). These plots show possible correlation in two stages (underlining the link between filling of the zeolite cavities during methanol conversion and increasing strain in the crystal structure, first observed in SAPO-34 $4^{4}$, with a steep gradient up to a channel occupancy of 0.05 and a lower gradient above. The gradients found are shown in Table 2. The correlations suggest that initial formation of small amounts of organic compounds in the channels causes a large increase in strain while the further development of larger species has less impact. Note that the 6.5 and $13 \mathrm{~mm}$ slices have very few points with an occupancy of below 0.05, suggesting that large intermediates form more quickly further from the inlet in agreement with our other observations. The large spread of these points also leads to rather large standard deviations in the values of slope 1 . The low levels of strain and also unit cell expansion in ZSM-5 compared to the MTO catalysts SAPO-34 and 18 are probably due to a more open channel system which does not contain large internal cavities where large polyaromatic molecules can 

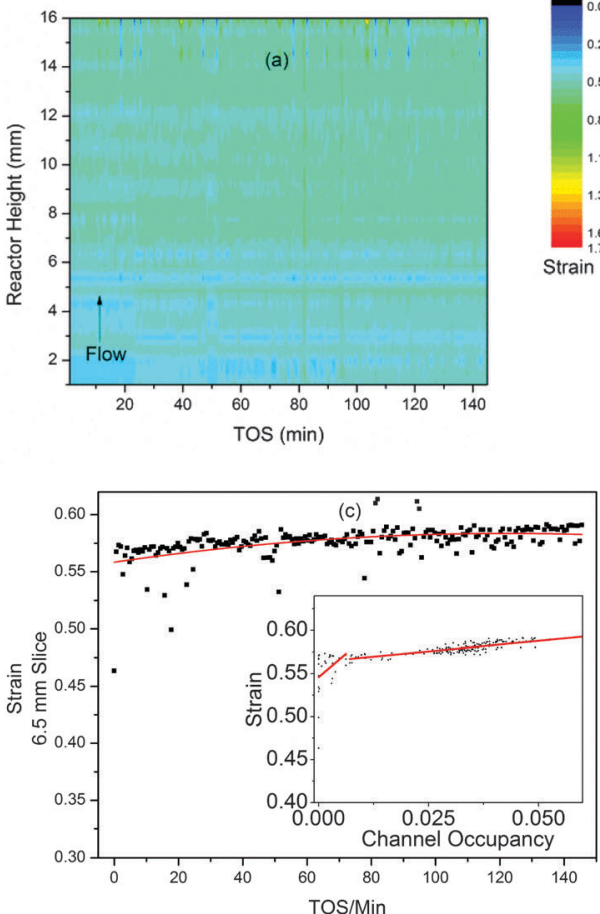
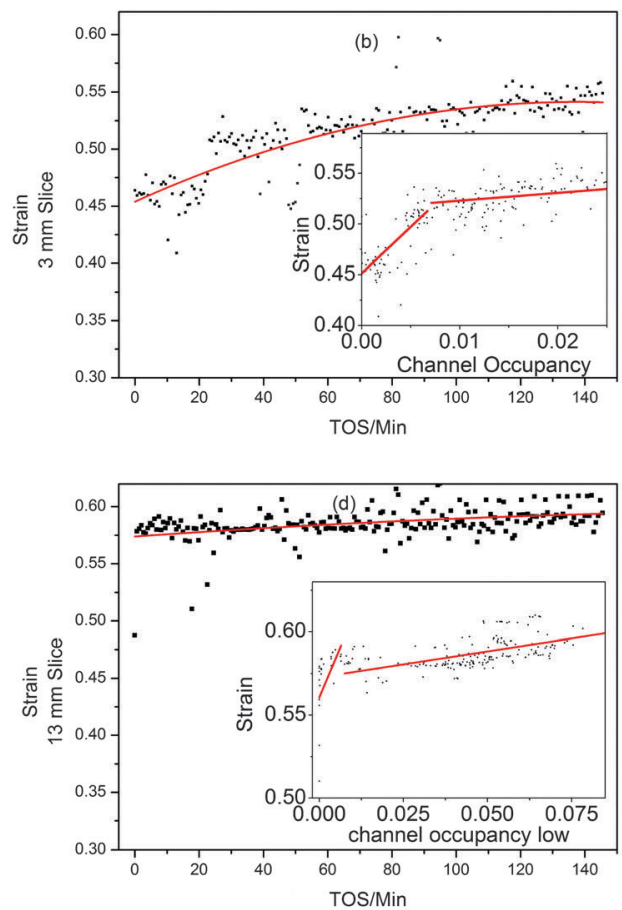

Fig. 9 Plots of the strain developed in ZSM-5 during the MTG process from Z-scanning HEPXRD data: (a) contour plot (colour scale for strain) for all data; (b-d) 2D plots of strain vs. TOS in slices 3,6.5 and $13 \mathrm{~mm}$ up the reactor bed with polynomial fit lines to display the trends in the data. The inset graphs (b-d) show plots of strain vs. channel occupancy with lines of best fit.

Table 2 Slopes for the two linear regression lines fitted to the strain vs. occupancy plots in Fig. 9

\begin{tabular}{lcl}
\hline Height $(\mathrm{mm})$ & Slope $1^{a}$ & Slope $2^{b}$ \\
\hline 3 & $9.1 \pm 1$ & $0.77 \pm 0.12$ \\
7 & $4.4 \pm 2$ & $0.48 \pm 0.03$ \\
13 & $4.8 \pm 2$ & $0.31 \pm 0.03$ \\
${ }^{a}$ Occupancy below $0.05 .{ }^{b}$ Occupancy greater than 0.05 &
\end{tabular}

build up and become entrapped - such molecules are seldom observed in the internal coke extracted from exhausted MTG catalysts by the acid dissolution method. ${ }^{52,76}$

\section{Conclusions}

This work illustrates the methods for analysis of large time and space resolved datasets by the Rietveld method. The comparisons with single point capillary in situ experiments and the analysis of the effects of variations in the refinement strategy show that the method is robust and the use of trend analysis to illustrate weak features of the dataset shows the value of having a large volume of data. The data on the MTG process over ZSM5 proved ideal for demonstrating this due to the very small impact of the reaction on the diffraction data, especially with regard to the unit cell parameters. We have also shown that data such as zeolite channel occupancy and crystallite strain can be reliably extracted from these data. In this case these data proved more informative than the unit cell parameters.
The results on the MTG process suggest that there are more or larger intermediates close to the reactor outlet (from the expansion and channel occupancy data); at least at short times on stream, and that these may well be aromatic in nature (from the shape of the occupancy curves compared to silicoaluminophosphate MTO catalysts). We also believe that strain in the ZSM-5 crystallites increases with the build-up of reaction intermediates as previously observed for SAPO-34 and 18 in the MTO process - however, in the case of ZSM-5 these effects are very weak compared to the two SAPOs, probably because of its more open channel systems.

\section{Acknowledgements}

We acknowledge funding from the Research Council of Norway through inGAP (contract no. 174893) and thank the ESRF for granting beamtime at ID15b. We also thank Shewangizaw Teketel Forsido and Stian Svelle for helpful discussions on the MTG mechanism and Wouter van Beek for the loan of the SNBL gas flow meter.

\section{References}

1 S. Kumar, F. Carniato, A. Arrais, G. Croce, E. Boccaleri, L. Palin, B. W. van and M. Milanesio, Cryst. Growth Des., 2009, 9, 3396-3404.

2 B. W. van, F. Carniato, S. Kumar, G. Croce, E. Boccaleri and M. Milanesio, Phase Transitions, 2009, 82, 293-302. 
3 D. S. Wragg, D. Akporiaye and H. Fjellvåg, J. Catal., 2011, 279, 397-402.

4 D. S. Wragg, R. E. Johnsen, M. Balasundaram, P. Norby, H. Fjellvåg, A. Grønvold, T. Fuglerud, J. Hafizovic, Ø. B. Vistad and D. Akporiaye, J. Catal., 2009, 268, 290-296.

5 D. S. Wragg, R. E. Johnsen, P. Norby and H. Fjellvåg, Microporous Mesoporous Mater., 2010, 134, 210-215.

6 M. Zokaie, D. S. Wragg, A. Grønvold, T. Fuglerud, J. H. Cavka, K. P. Lillerud and O. Swang, Microporous Mesoporous Mater., 2013, 165, 1-5.

7 R. J. Francis and D. O'Hare, J. Chem. Soc., Dalton Trans., 1998, 3133-3148.

8 P. Norby, Curr. Opin. Colloid Interface Sci., 2006, 11, 118.

9 M. A. Newton and W. van Beek, Chem. Soc. Rev., 2010, 39, 4845-4863.

10 M. G. O’Brien, A. M. Beale, S. D. M. Jacques, M. M. Di and B. M. Weckhuysen, ChemCatChem, 2009, 1, 99-102.

11 P. Norby, J. Am. Chem. Soc., 1997, 119, 5215-5221.

12 G. Agostini, C. Lamberti, L. Palin, M. Milanesio, N. Danilina, B. Xu, M. Janousch and B. J. A. van, J. Am. Chem. Soc., 2010, 132, 667-678.

13 M. Sanchez del Rio, E. Boccaleri, M. Milanesio, G. Croce, B. W. van, C. Tsiantos, G. D. Chyssikos, V. Gionis, G. H. Kacandes, M. Suarez and E. Garcia-Romero, J. Mater. Sci., 2009, 44, 5524-5536.

14 A. M. Beale, M. G. O’Brien, M. Kasunic, A. Golobic, M. Sanchez-Sanchez, A. J. W. Lobo, D. W. Lewis, D. S. Wragg, S. Nikitenko, W. Bras and B. M. Weckhuysen, J. Phys. Chem. C, 2011, 115, 6331-6340.

15 M. G. O’Brien, A. M. Beale and B. M. Weckhuysen, Chem. Soc. Rev., 2010, 39, 4767-4782.

16 M. Feyand, A. Huebner, A. Rothkirch, D. S. Wragg and N. Stock, Inorg. Chem., 2012, 51, 12540-12547.

17 D. S. Wragg, P. J. Byrne, G. Giriat, O. B. Le, R. Gyepes, A. Harrison, A. G. Whittaker and R. E. Morris, J. Phys. Chem. C, 2009, 113, 20553-20558.

18 P. D. C. Dietzel, R. E. Johnsen, R. Blom and H. Fjellvag, Chem.-Eur. J., 2008, 14, 2389-2397.

19 R. E. Johnsen, F. Krumeich and P. Norby, J. Appl. Crystallogr., 2010, 43, 434-447.

20 R. E. Johnsen and P. Norby, J. Appl. Crystallogr., 2008, 41, 991-1002.

21 R. E. Johnsen and P. Norby, J. Phys. Chem. C, 2009, 113, 19061-19066.

22 J. E. Daniels and M. Drakopoulos, J. Synchrotron Radiat., 2009, 16, 463-468.

23 G. W. Stinton and J. S. O. Evans, J. Appl. Crystallogr., 2007, 40, 87-95.

24 A. M. Beale, S. D. M. Jacques and B. M. Weckhuysen, Chem. Soc. Rev., 39, 4656-4672.

25 D. S. Wragg, M. G. O’Brien, F. L. Bleken, M. Di Michiel, U. Olsbye and H. Fjellvåg, Angew. Chem., Int. Ed., 2012, 51, 7956-7959.

26 M. G. O’Brien, A. M. Beale, S. D. M. Jacques, M. Di Michiel and B. M. Weckhuysen, Appl. Catal., A., 2011, 391, 468-476.

27 F. Millange, C. Serre, N. Guillou, G. Ferey and R. I. Walton, Angew. Chem., Int. Ed., 2008, 47, 4100-4105.
28 F. Salles, G. Maurin, C. Serre, P. L. Llewellyn, C. Knofel, H. J. Choi, Y. Filinchuk, L. Oliviero, A. Vimont, J. R. Long and G. Ferey, J. Am. Chem. Soc., 2010, 132, 13782-13788.

29 L. Espinosa-Alonso, M. G. O’Brien, S. D. M. Jacques, A. M. Beale, J. de, P. Barnes and B. M. Weckhuysen, J. Am. Chem. Soc., 2009, 131, 16932-16938.

30 A. M. Beale, S. D. M. Jacques and B. M. Weckhuysen, Chem. Soc. Rev., 2010, 39, 4656-4672.

31 S. D. M. Jacques, M. M. Di, A. M. Beale, T. Sochi, M. G. O'Brien, L. Espinosa-Alonso, B. M. Weckhuysen and P. Barnes, Angew. Chem., Int. Ed., 2011, 50, 10148-10152.

32 M. G. O'Brien, S. D. M. Jacques, M. M. Di, P. Barnes, B. M. Weckhuysen and A. M. Beale, Chem. Sci., 2012, 3, 509-523.

33 M. G. O’Brien, A. M. Beale, S. D. M. Jacques, T. Buslaps, V. Honkimaki and B. M. Weckhuysen, J. Phys. Chem. C, 2009, 113, 4890-4897.

34 A. A. Coelho, TOPAS v4.2, Bruker AXS, 2006.

35 G. T. Kokotailo, S. L. Lawton, D. H. Olson and W. M. Meier, Nature, 1978, 272, 437-438.

36 C. D. Chang, Catal. Rev., 1983, 25, 1-118.

37 J. F. Haw, S. M. Auerbach, K. A. Carrado and P. K. Dutta, Handbook of Zeolite Science and Technology, 2003.

38 P. Barger, M. Guisnet and J.-P. Gilson, Zeolites for cleaner technologies: catalytic science series, 2002.

39 U. Olsbye, M. Bjørgen, S. Svelle, K.-P. Lillerud and S. Kolboe, Catal. Today, 2005, 106, 108-111.

40 U. Olsbye, S. Svelle, M. Bjørgen, P. Beato, T. V. W. Janssens, F. Joensen, S. Bordiga and K. P. Lillerud, Angew. Chem., Int. Ed., 2012, 51, 5810-5831.

41 M. Stöcker, Microporous Mesoporous Mater., 1999, 29, 3-48.

42 C. D. Chang, Shape Selective Catalysis: Chemical Synthesis and Hydrocarbon Processing, 2000.

43 S. Svelle, C. Tuma, X. Rozanska, T. Kerber and J. Sauer, J. Am. Chem. Soc., 2008, 131, 816-825.

44 V. Van Speybroeck, J. Van der Mynsbrugge, M. Vandichel, K. Hemelsoet, D. Lesthaeghe, A. Ghysels, G. B. Marin and M. Waroquier, J. Am. Chem. Soc., 2010, 133, 888-899.

45 D. Mores, E. Stavitski, M. H. F. Kox, J. Kornatowski, U. Olsbye and B. M. Weckhuysen, Chem.-Eur. J., 2008, 14, 11320-11327.

46 D. Mores, J. Kornatowski, U. Olsbye and B. M. Weckhuysen, Chem.-Eur. J., 2011, 17, 2874-2884.

47 L. R. Aramburo, S. E. de, B. Arstad, S. M. M. van, L. Sommer, A. Juhin, T. Yokosawa, H. W. Zandbergen, U. Olsbye, G. F. M. F. de and B. M. Weckhuysen, Angew. Chem., Int. Ed., 2012, 51, 3616-3619.

48 L. Sommer, S. Svelle, K. P. Lillerud, M. Stocker, B. M. Weckhuysen and U. Olsbye, Langmuir, 2010, 26, 16510-16516.

49 D. M. Marcus, M. J. Hayman, Y. M. Blau, D. R. Guenther, J. O. Ehresmann, P. W. Kletnieks and J. F. Haw, Angew. Chem., 2006, 118, 1967-1969.

50 D. M. Marcus, M. J. Hayman, Y. M. Blau, D. R. Guenther, J. O. Ehresmann, P. W. Kletnieks and J. F. Haw, Angew. Chem., Int. Ed., 2006, 45, 1933-1935. 
51 F. Bleken, W. Skistad, K. Barbera, M. Kustova, S. Bordiga, P. Beato, K. P. Lillerud, S. Svelle and U. Olsbye, Phys. Chem. Chem. Phys., 2011, 13, 2539-2549.

52 P. Magnoux, P. Roger, C. Canaff, V. Fouche, N. S. Gnep and M. Guisnet, in Studies in Surface Science and Catalysis, ed. B. Delmon and G. F. Froment, Elsevier, 1987, vol. 34, pp. 317-330.

53 S. Svelle, L. Sommer, K. Barbera, P. N. R. Vennestrøm, U. Olsbye, K. P. Lillerud, S. Bordiga, Y.-H. Pan and P. Beato, Catal. Today, 2011, 168, 38-47.

54 K. Barbera, F. Bonino, S. Bordiga, T. V. W. Janssens and P. Beato, J. Catal., 2011, 280, 196-205.

55 P. M. Allotta and P. C. Stair, ACS Catal., 2012, 2, 2424-2432.

56 Y. T. Chua and P. C. Stair, J. Catal., 2003, 213, 39-46.

57 Y. T. Chua, P. C. Stair, J. B. Nicholas, W. Song and J. F. Haw, J. Am. Chem. Soc., 2003, 125, 866-867.

58 Y. T. Chua, P. C. Stair, J. B. Nicholas, W. Song and J. F. Haw, J. Am. Chem. Soc., 2003, 125, 866-867.

59 F. L. Bleken, S. Chavan, U. Olsbye, M. Boltz, F. Ocampo and B. Louis, Appl. Catal., A, 2012, 447-448, 178-185.

$60 \mathrm{H}$. van Koningsveld, F. Tuinstra, H. van Bekkum and J. C. Jansen, Acta Crystallogr., Sect. B: Struct. Sci., 1989, 45, 423-431.

61 H. Gies, B. Marler, C. Fyfe, G. Kokotailo, Y. Feng and D. E. Cox, J. Phys. Chem. Solids, 1991, 52, 1235-1241.

62 B. F. Mentzen, Mater. Res. Bull., 1992, 27, 953-960.

63 B. F. Mentzen, M. Sacerdote-Peronnet, J.-F. Bérar and F. Lefebvre, Zeolites, 1993, 13, 485-492.

64 B. F. Mentzen and M. Sacerdote-peronnet, Mater. Res. Bull., 1993, 28, 1161-1168.

65 B. F. Mentzen, R. Favre and F. Cauwet, Mater. Res. Bull., 1994, 29, 587-594.

66 B. F. Mentzen and P. Gelin, Mater. Res. Bull., 1995, 30, 373-380.

67 H. van Koningsveld and J. C. Jansen, Microporous Mater., 1996, 6, 159-167.

68 H. van Koningsveld, J. C. Jansen and A. J. M. d. Man, Acta Crystallogr., Sect. B: Struct. Sci., 1996, 52, 131-139.

69 H. van Koningsveld, J. C. Jansen and H. van Bekkum, Acta Crystallogr., Sect. B: Struct. Sci., 1996, 52, 140-144.

70 H. van Koningsveld and J. H. Koegler, Microporous Mater., 1997, 9, 71-81.
71 B. F. Mentzen and F. Lefebvre, Mater. Res. Bull., 1997, 32, 813-820.

72 B. Mentzen and F. Lefèbvre, J. Chim. Phys., 1998, 95, 1052-1067.

73 H. van Koningsveld, J. Mol. Catal. A: Chem., 1998, 134, 89-95.

74 H. Morell, K. Angermund, A. R. Lewis, D. H. Brouwer, C. A. Fyfe and H. Gies, Chem. Mater., 2002, 14, 2192-2198.

75 K. Nishi, A. Hidaka and Y. Yokomori, Acta Crystallogr., Sect. B: Struct. Sci., 2005, 61, 160-163.

76 F. L. Bleken, T. V. W. Janssens, S. Svelle and U. Olsbye, Microporous Mesoporous Mater., 2012, 164, 190-198.

77 C. D. Chang and A. J. Silvestri, J. Catal., 1977, 47, 249-259.

78 M. Ronning, N. E. Tsakoumis, A. Voronov, R. E. Johnsen, P. Norby, B. W. van, O. Borg, E. Rytter and A. Holmen, Catal. Today, 2010, 155, 289-295.

79 N. E. Tsakoumis, R. Dehghan, R. E. Johnsen, A. Voronov, B. W. van, J. C. Walmsley, O. Borg, E. Rytter, D. Chen, M. Roenning and A. Holmen, Catal. Today, 2013, 205, 86-93.

80 N. E. Tsakoumis, A. Voronov, M. Ronning, B. W. van, O. Borg, E. Rytter and A. Holmen, J. Catal., 2012, 291, 138-148.

81 A. P. Hammersley, http:/www.esrf.eu/computing/scientific/ FIT2D/.

82 A. P. Hammersley, S. O. Svensson, M. Hanfland, A. N. Fitch and D. Hausermann, High Pressure Res., 1996, 14, 235-248.

83 H. van Koningsveld, H. van Bekkum and J. C. Jansen, Acta Crystallogr., Sect. B: Struct. Sci., 1987, 43, 127-132.

84 T. J. DiCiccio and B. Efron, Stat. Sci., 1996, 11, 189-212.

85 M. R. Rowles, personal communication.

86 F. Bleken, M. Bjørgen, L. Palumbo, S. Bordiga, S. Svelle, K.-P. Lillerud and U. Olsbye, Top. Catal., 2009, 52, 218-228.

87 H. van Koningsveld, Acta Crystallogr., Sect. B: Struct. Sci., 1990, 46, 731-735.

88 H. Schulz, Catal. Today, 2010, 154, 183-194.

89 M. Bjørgen, S. Svelle, F. Joensen, J. Nerlov, S. Kolboe, F. Bonino, L. Palumbo, S. Bordiga and U. Olsbye, J. Catal., 2007, 249, 195-207.

90 P. Barger, in Zeolite for Cleaner Technologies, ed. M. Guisnet and J.-P. Gilson, Imperial College Press, London, 2002, vol. 3 , ch. 12 , pp. 239-260. 